\title{
THE EFFECT OF DIGITALIS ON THE VENOUS PRESSURE OF NORMAL INDIVIDUALS
}

\author{
By DAVID A. RYTAND \\ (From the Department of Medicine, Stanford Unicersity, School of Medicine, \\ San Francisco)
}

(Received for publication April 17, 1933)

That the administration of digitalis in heart failure causes an increase in cardiac output (per minute and per beat) and a fall in venous pressure is well known (1). It is also well established that the exhibition of digitalis to normal men and dogs results in a decreased output $(2,3,4,5,6,7)$, but data on venous pressure in normal individuals following digitalis are inconclusive.

In animals. Villaret, Grellety-Bosviel and coworkers (8) found a fall of venous pressure after intravenous injection of ouabain. Kaufmann (9), Popper (10), and Dock and Tainter $(5,6)$ found a decreased venous pressure following intravenous injection of strophanthin and digitalis. Plumier (11) noted increased venous pressure after strophanthin and digitoxin. Yokota (12) found a small decrease, greater decrease, and increase in venous pressure with intravenous injection of small, medium, and large doses, respectively, of strophanthin. Capps and Matthews (13) found no change after digitalis.

In man. Stewart and Cohn (7) found a marked fall in venous pressure in one normal subject after oral administration of digitan, using the Moritz-Tabora (20) technique of venous pressure determination. Simultaneously in the first subject, and in two other subjects, they found no constant change when a less accurate method was used (that of allowing blood to rise in a dry tube).

As Eyster (14) pointed out, it is impossible to determine whether the changes produced by digitalis in output are cardiac or extra-cardiac in origin unless the changes in venous pressure are known. In decompensated hearts it is agreed $(5,7)$ that the increased output is due largely to the change in ventricular tone, any peripheral action of digitalis being relatively unimportant (although Wollheim (15) and others $(16,17)$ credit the reduction in effective (systemic) blood volume with more importance in relieving congestive failure).

Opinion differs widely, however, regarding the origin of the digitalis effects in the normal organism. Cohn and his coworkers $(7,18,19)$, unable to demonstrate venous pressure changes, hold that the decreased cardiac output is due to diminished ventricular filling caused by increased tone 
of the heart muscle. Dock and Tainter $(5,6)$, on the other hand, believe that the decreased output is due to diminished ventricular filling caused by lowered venous pressure (with lessened return flow of blood to the heart), which they have shown to be the result of pooling of blood in the portal system.

Grollman (1) states that "it is impossible at present to say definitely if the primary cause of the observed decrease in the cardiac output following administration of digitalis to normal individuals is due to its action on the heart or on peripheral structures." This study was designed to obtain clata on the height of venous pressure before and after the administration of full doses of digitalis to normal human beings to determine whether the question of cardiac or extra-cardiac action of the drug in decreasing output could be answered.

\section{METHODS}

Thirty-seven control and 82 experimental observations were made on venous pressure before and after the administration of digitalis (in single doses) in 9 trials on 8 normal subjects.

Apparatus and techniquc. The method used was one of the direct (venepuncture) types, a simplification of the Moritz-Tabora (20) technique as suggested by Dock. The system consisted of an intravenous needle and a manometer (a straight $20 \mathrm{~cm}$. length of glass tubing, $3 \mathrm{~mm}$. inside diameter), connected by means of a Kaufmann-Luer syringe. The needle and syringe were boiled before each determination, while the manometer was kept in 95 per cent alcohol.

Before use, the system was connected and filled with sterile physiological saline to avoid the misleading effects of the viscosity of a blood column rising in a dry tube. The saline-filled system was suspended over the antecubital fossa of the subject and venepuncture performed in the usual aseptic manner. The plunger of the syringe was then withdrawn until the manometer was in direct communication with the vein, and fastened in place. The column of saline was allowed to fall in the manometer until equilibrium was reached, when the height of the top of the column above the vein was read. Eight millimeters (found by trial) was subtracted from each reading to allow for capillarity.

Each reading was made with the subject in the supine position on a thin mattress without sag, so that the olecranon and the dorsum of the thorax were on the same plane. To avoid the effects of exercise (21) the subjects assumed this position 20 to 30 minutes before each determination. No readings were taken immediately after the subjects had eaten. Room temperature was approximately constant.

All clothing above the waist was removed. Stasis for venepuncture was momentary only. After each reading, the upper arm was compressed to insure patency of the needle and to allow the saline to rise and fall again for a confirmatory reading. Because of the number of venepunctures in each subject, both arms were used, preliminary observations having shown that this proceeding introduced no error.

No effort was made to approximate the level of the antecubital vein to that of the right auricle, as we were more interested in following changes from hour to hour in any given subject and felt that accuracy would be sacrificed if an attempt were made to obtain absolute venous pressure (22). 
Subjects. There were 8 subjects, 6 men and 2 women. Age varied from 33 to 63 years. Two series of observations were made on one woman. All subjects were ambulatory patients on the neuro-psychiatry ward, diagnosed psychoneurosis, psychasthenia, involutional melancholia, and schizophrenia. Most of them cooperated nicely. None showed any evidence of cardiovascular abnormalities; in particular, there were absolutely no signs or symptoms of cardiac decompensation in any subject. None of these patients experienced the symptoms of pain, lassitude, or dyspnea noted by Stewart and Cohn (7) after digitalis administration.

Digitalis. The digitalis powder used was kindly supplied and standardized by Doctor A. B. Stockton. It assayed $108 \mathrm{mgm}$. to one Hatcher cat unit (predicted clinical dose $=21$ to $35 \mathrm{mgm}$. per $\mathrm{kgm}$.), and $25 \mathrm{mgm}$. to one pigeon emetic dose (predicted clinical dose $=25 \mathrm{mgm}$. per $\mathrm{kgm}$.). The dosage varied from 1.0 to $1.6 \mathrm{gram}$ ( 19.2 to $30.0 \mathrm{mgm}$. per $\mathrm{kgm}$.). Each subject received the powder in one dose; at six o'clock in the morning, before breakfast.

\section{RESULTS}

The initial venous pressure determinations in five of the subjects were obviously fallacious, being 2.2, 4.1 , and $4.9 \mathrm{~cm}$. higher than the average of the remaining control observations in three cases, and 11.0 and $3.1 \mathrm{~cm}$. lower in two. In another instance, a single reading $6.8 \mathrm{~cm}$. higher was found. All of these erroneous values were discarded in the computations of results and do not appear in the figures or tables: the net result of discarding these observations is to minimize slightly the venous pressure decrease to be pointed out below.

There are 37 control observations distributed over 9 series. The variabilities $(100 \sigma /$ Mean $)$ of the series are $14.1,11.7,11.4,10.1,7.3,7.1,6.4$, 4.2 , and 3.2 per cent, respectively. The average variability is 8.4 per cent. There are $\$ 2$ observations after digitalis.

An afternoon rise of venous pressure was noted in 4 of 6 series of control observations. The mean afternoon rise in these 6 series was $0.4 \mathrm{~cm}$. of saline. This is in the same direction, but of much less degree, than the diurnal variation noted with an indirect method by Hooker (23). No correction for this small variation was made in the computations.

The control and experimental results are summarized in Table 1 (hours approximated), Table 2, and Figure 1. It is evident that digitalis caused a fall of venous pressure of greatest degree (minus $1.96 \mathrm{~cm}$. saline) at 24 to 32 hours after administration, with a return to the control level at 72 to 96 hours.

\section{DISCUSSION}

In Figure 2 (data in Table 3 ) is represented a comparison of our results on venous pressure $(A)$ with those of Cohn and Stewart $(4,7)$ on cardiac output in humans $(B)$ and in $\operatorname{dogs}(C)$. All means are computed by averaging observations about their respective modes. 


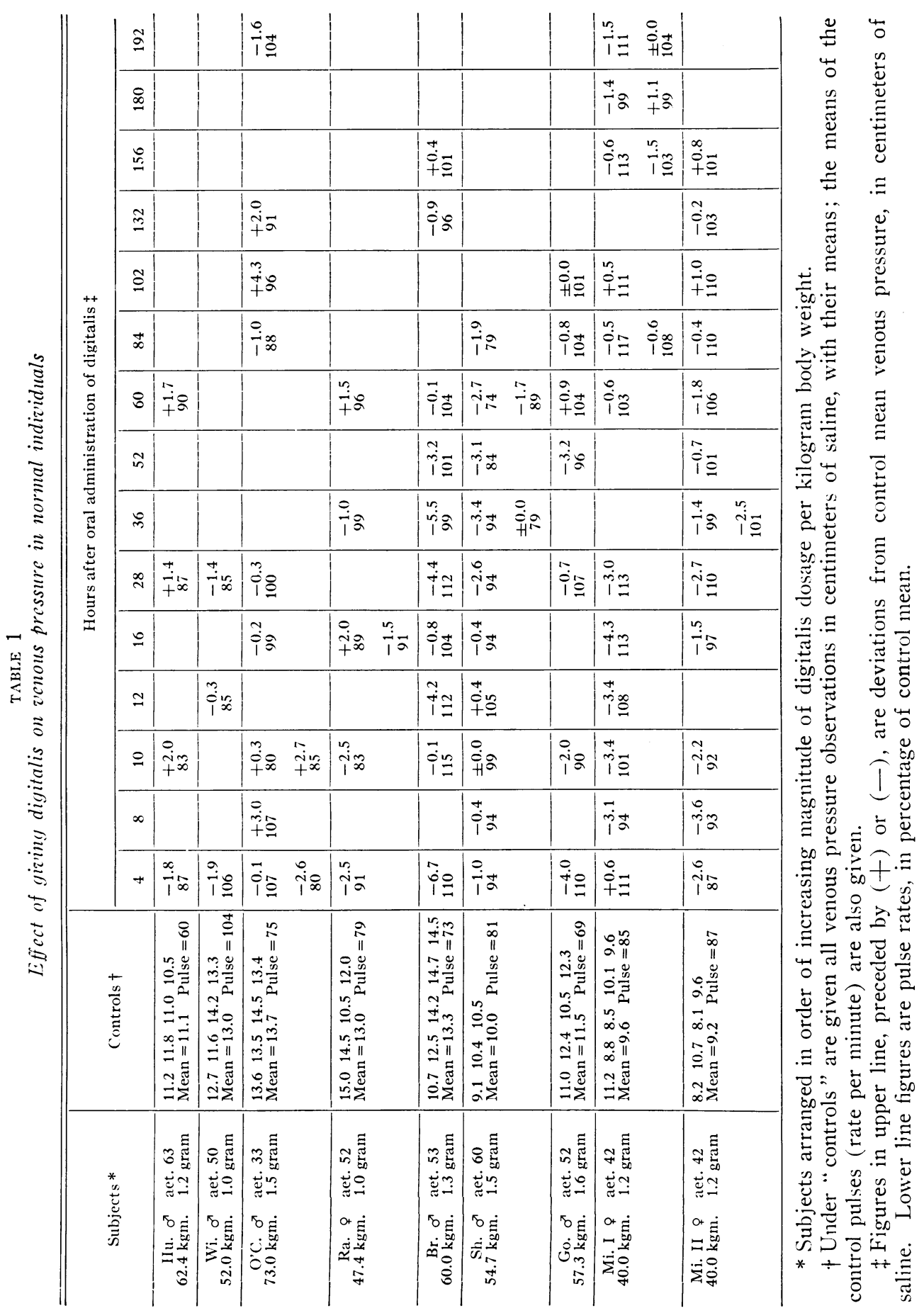


TABLE 2

Effect of giving digitalis on the venous pressure of normal individuals. Means of all observations

\begin{tabular}{c|c|c|c|c}
\hline $\begin{array}{c}\text { Hours after } \\
\text { administration } \\
\text { of digitalis }\end{array}$ & $\begin{array}{c}\text { Range of } \\
\text { hours after } \\
\text { digitalis }\end{array}$ & $\begin{array}{c}\text { Number } \\
\text { of } \\
\text { observations }\end{array}$ & $\begin{array}{c}\text { Venous pressure. } \\
\text { Deviation from } \\
\text { control mean }\end{array}$ & $\begin{array}{c}\text { Pulse rate. } \\
\text { Percentage of } \\
\text { control mean }\end{array}$ \\
\hline hours & hours & number & cm. saline & per cent \\
9.3 & $4-17$ & 34 & -1.35 & 97.0 \\
31.7 & $28-38$ & 14 & -1.96 & 98.5 \\
57.3 & $52-62$ & 12 & -1.08 & 95.6 \\
88.9 & $76-104$ & 10 & +0.06 & 102.5 \\
167.8 & $120-270$ & 12 & -0.28 & 102.1 \\
& $4-5$ & 10 & & 98.3 \\
4.8 & $7-10$ & 13 & -2.26 & 93.6 \\
9.2 & $11-17$ & 11 & -1.29 & 99.7 \\
13.5 & & 34 & & \\
\hline
\end{tabular}

In the lower part of the table, the observations in the first 17 hours are further separated. The comparatively high venous pressure in the 7-10 hour range is due to the slow pulse (93.6 per cent). See discussion in text.

Direction of changes. Digitalis, in normal individuals, causes a decrease in both cardiac output and venous pressure. It is axiomatic that a cardiac cause for diminished output will result in an increased venous pres-

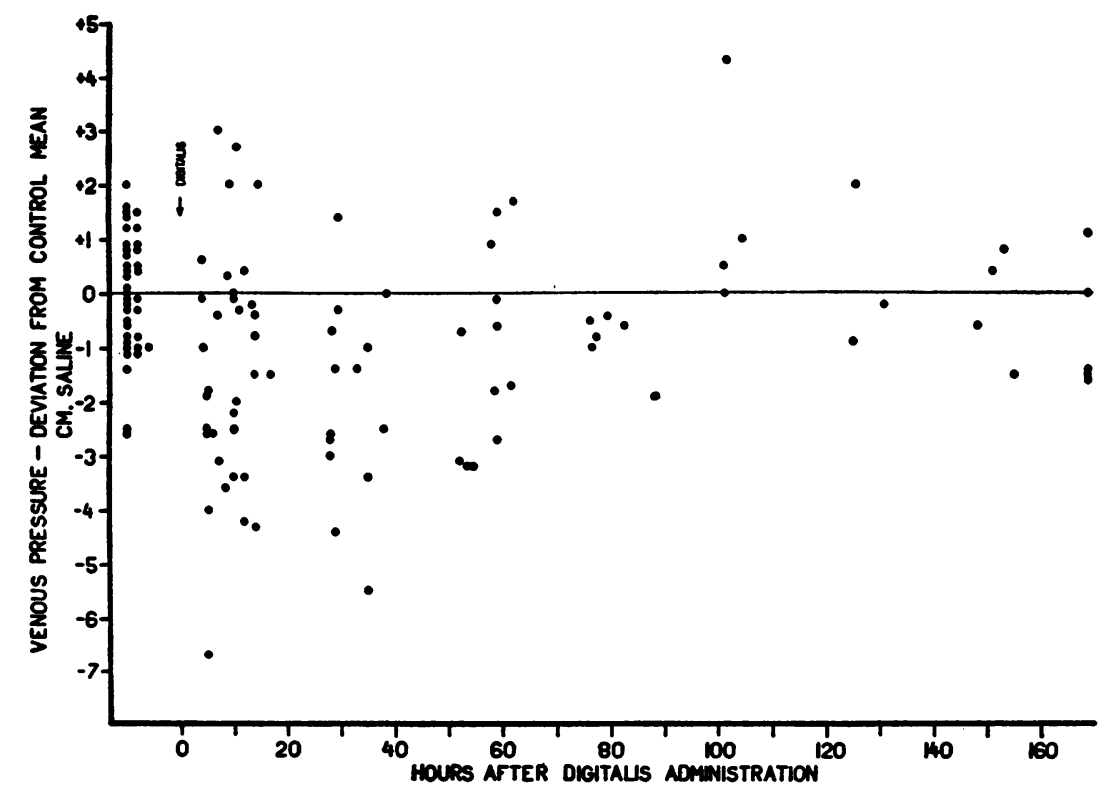

Fig. 1. Scatter Diagram Showing All Observations 
sure, and that an extra-cardiac production of lowered venous pressure will bring about a decreased cardiac output.

Duration of changes. The time relations of venous pressure changes to cardiac output changes are similar. The lowest mean venous pressure

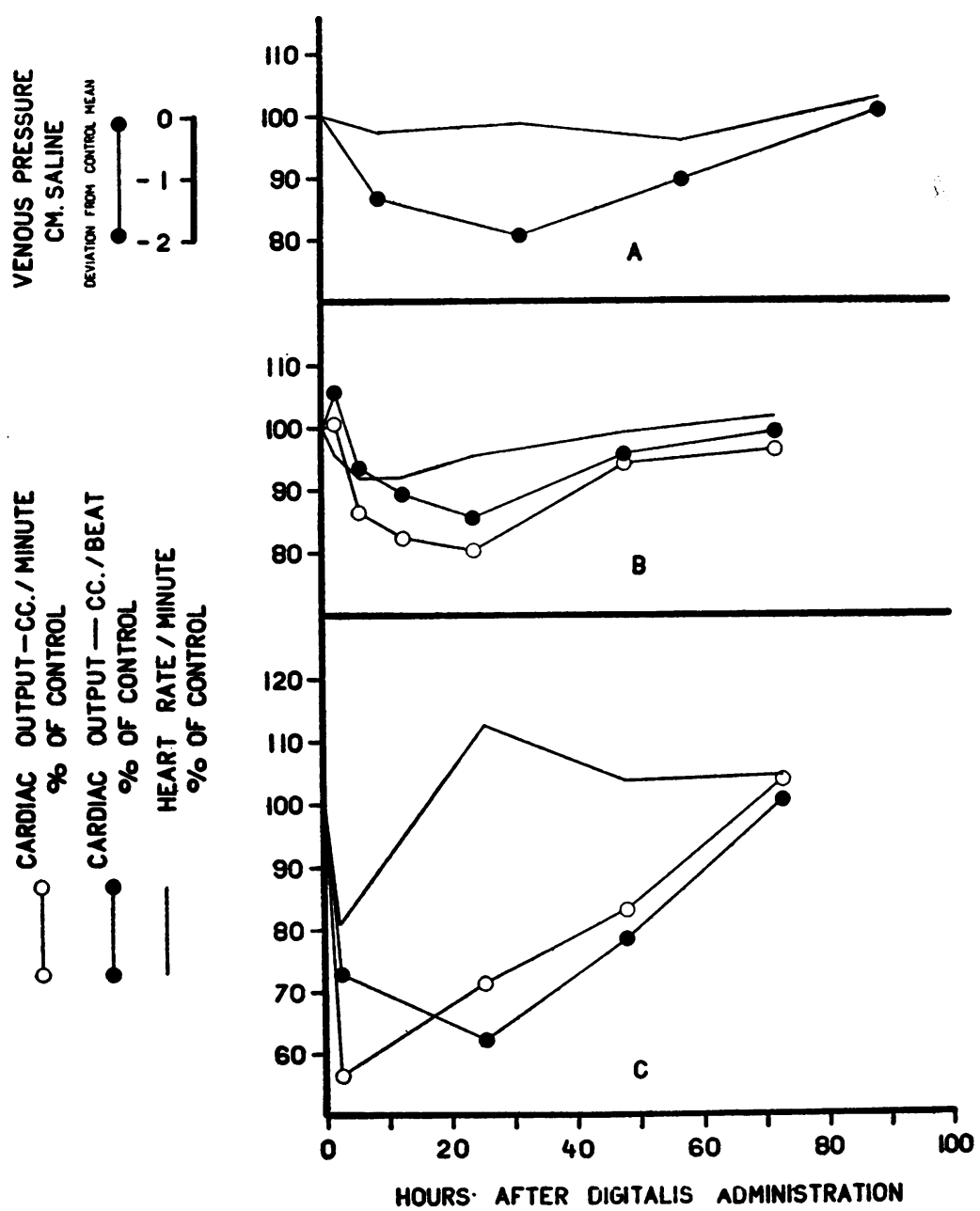

Fig. 2. The Effect of Digitalis on Venous Pressure and Cardiac OUtPut in Normal Individuals (4).

$A$. Venous pressure. $B$. Output in human beings (7). C. Output in dogs

occurred at 31.7 hours, while the minute and stroke volume in man fell to their lowest values at 24 hours (after oral administration of digitalis). The 8 hour difference is probably due to the paucity of observations and to the necessity of averaging observations about their modes. In dogs, be- 
TABLE 3

The effects of digitalis administration on venous pressure and on cardiac output: $A$ comparison

\begin{tabular}{c|c|c|c|c|c}
\hline \hline $\begin{array}{c}\text { Hours after } \\
\text { digitalis } \\
\text { administration }\end{array}$ & $\begin{array}{c}\text { Number } \\
\text { of } \\
\text { observations }\end{array}$ & $\begin{array}{c}\text { Venous pressure. } \\
\text { Deviation from } \\
\text { control mean }\end{array}$ & $\begin{array}{c}\text { Stroke volume. } \\
\text { Percentage } \\
\text { of control }\end{array}$ & $\begin{array}{c}\text { Minute volume. } \\
\text { Percentage } \\
\text { of control }\end{array}$ & $\begin{array}{c}\text { Pulse rate. } \\
\text { Percentage } \\
\text { of control }\end{array}$ \\
\hline hours & number & cm. saline & per cent & per cent & per cent \\
\hline
\end{tabular}

$A$. Venous pressure in the normal human being

\begin{tabular}{r|r|r|r|r|r}
\hline 9.3 & 34 & -1.35 & & & 97.0 \\
31.7 & 14 & -1.96 & & & 98.5 \\
57.3 & 12 & -1.08 & & & 95.6 \\
88.9 & 10 & +0.06 & & & 102.5 \\
\hline
\end{tabular}

$B$. Cardiac output in the normal human being (7)

\begin{tabular}{|c|c|c|c|c|}
\hline $\begin{array}{r}2 \\
6 \\
13 \\
24 \\
48 \\
72\end{array}$ & $\begin{array}{r}2 \\
10 \\
8 \\
7 \\
6 \\
4\end{array}$ & $\begin{array}{r}105.5 \\
93.4 \\
89.3 \\
85.4 \\
95.6 \\
99.0\end{array}$ & $\begin{array}{r}100.5 \\
86.4 \\
82.1 \\
80.1 \\
95.2 \\
96.2\end{array}$ & $\begin{array}{r}95.5 \\
92.5 \\
92.2 \\
95.4 \\
99.1 \\
101.5\end{array}$ \\
\hline
\end{tabular}

C. Cardiac output in the normal dog (4)

\begin{tabular}{|c|c|c|c|c|}
\hline $\begin{array}{l}2.5 \\
25.5 \\
48 \\
73\end{array}$ & $\begin{array}{r}11 \\
12 \\
3 \\
4\end{array}$ & $\begin{array}{r}72.9 \\
62.2 \\
78.4 \\
100.5\end{array}$ & $\begin{array}{r}56.5 \\
71.2 \\
83.0 \\
103.8\end{array}$ & $\begin{array}{r}80.9 \\
112.5 \\
103.7 \\
104.5\end{array}$ \\
\hline
\end{tabular}

cause of the intravenous administration of the drug, time relationships are not strictly comparable; even here, however, the stroke volume is lowest at 25.5 hours.

Venous pressure returned to the control level between 72 and 96 hours after digitalis. Cardiac output in man reached normal values in 72 hours (stroke volume 99.0 and minute volume 96.2 per cent of their respective controls). Cardiac output in dogs was slightly above the control in 73 hours. (The apparent 16 day duration of depressed output in Stewart and Cohn's (7) Subject 1 is undoubtedly due to a high control reading, for the values at $4,5,7$, and 16 days after digitalis are remarkably constant-87, 89,88 , and 82 per cent of the control minute volume, respectively.)

The effect of digitalis on the $\mathrm{A}-\mathrm{V}$ conduction time and $\mathrm{T}$ wave of the electrocardiogram disappears in 5 to 22 days $(24,25)$. We made no electrocardiographic studies, but with the doses used the calculated duration of conduction time and $T$ wave effects in our series would be 8 to 14 days (26).

The duration of digitalis action on both cardiac output and venous pressure is more fleeting, then, than on the central $T$ wave and $A-V$ con- 
duction time changes. It is more prolonged than the rise of arterial pressure in dogs.

Degree of changes. Dock and Tainter (5) found in their dogs F4 and F5 that falls in venous pressure of 3.5 and $6.5 \mathrm{~cm}$. of water corresponded to minute output reductions of 41 and 55 per cent of controls, respectively. On the average, $1.0 \mathrm{~cm}$. of venous pressure was equivalent to 10.1 per cent of minute volume. Beck and Isaac (27) found, in experimental cardiac tamponade studies, that a $3.3 \mathrm{~cm}$. rise in venous pressure was associated with a 36 per cent reduction in cardiac output, and a $10.0 \mathrm{~cm}$. rise with a 64 per cent reduction. Thus, $1.0 \mathrm{~cm}$. of venous pressure was equivalent to 8.6 per cent of minute volume. Wiggers (28) presents a figure showing increasing systolic discharge in parallel with experimentally increased venous pressure (heart rate constant). Measurements taken from this figure permit the calculation that $1.0 \mathrm{~cm}$. of venous pressure is equivalent to 10.87 per cent of stroke volume.

Figure 2, in which the venous pressures of one group of subjects are compared with the cardiac outputs of a similarly studied group, shows that at the time of the maximal digitalis effect in man the venous pressure had fallen $1.96 \mathrm{~cm}$. and the minute and stroke volumes 19.9 and 14.6 per cent of their respective controls : that is, a $1.0 \mathrm{~cm}$. venous pressure change corresponded to a 10.15 and a 7.45 per cent change in minute and stroke volumes.

From a comparison of our results with those of Cohn and Stewart $(4,7)$, it is evident that venous pressure and cardiac output changes in normal individuals after digitalis correlate remarkably well in direction, time, and degree. The observations on direction can be explained only by a peripheral mechanism of digitalis action; those on time support such a mechanism, for the change in venous pressure and cardiac output (like that in arterial pressure in dogs) is less prolonged than the effect on the $T$ wave and conduction time; the degree of the venous pressure change is sufficient to explain the observed fall of cardiac output. The correlation which Stewart and Cohn (7) make between output and cardiac area is not so well marked as that between output and venous pressure, and neither supports nor controverts either the cardiac or extra-cardiac hypothesis of digitalis action.

The question of cardiac tone. According to Cohn and Steele (18), digitalis decreases cardiac output in normal cardiovascular systems by an increase in cardiac tone: the only evidence presented that the tone is increased is that of Cohn and Stewart (4). The latter observers found, radiographically, that the hearts of normal dogs became smaller and exhibited greater ventricular excursions after digitalis.

Cohn and Steele (18) state "since, in the experiments of Cohn and Stewart (4), the measurements were made during periods when the dogs were in so-called basal states, the work which their hearts performed may 
be regarded as constant, and the effects on diastolic size, as measures of the effect of digitalis on tone." Obviously, heart work is a function of the output per beat and is not, as Cohn and Steele suggest, measured by the oxygen consumption of the entire organism. Starling and Visscher (29) have demonstrated that diastolic volume varies with heart work, so that the decreased size of the heart observed by Cohn and Stewart $(4,7)$ should occur as a result of the decreased output. In expelling equal quantities of blood, a small heart must make greater excursions than does a larger heart. This fact amply explains the observations of Cohn and Stewart (4) without the necessity of invoking changes of tone. The effect is great enough to exist despite the decreased volume which the small heart ejects after digitalis.

Cohn and Steele (18) further state "the decrease in volume output which has been noticed was thought to result from the tonic effect of digitalis upon the heart (4), in consequence of which its size diminished so much, that a large or even a usual volume of blood could not be received and, therefore, could not be ejected." If this were the case, venous pressure should rise, as it does in cardiac tamponade (27); we have demonstrated, on the contrary, that venous pressure actually falls. Moreover, Wiggers and Stimson (30) showed by intraventricular pressure curves that the heart under digitalis offers no more resistance to inflowing blood than does the normal undigitalized heart.

Finally, Tainter (31) was able to reproduce the typical digitalis effects of decreased output and lowered venous pressure in cats with the Gibbs artificial heart apparatus, in which preparation the heart is replaced by a mechanical pump and in which, therefore, there could be absolutely no question of changes in "heart tone."

Relation of venous pressure to pulse rate. If digitalis bradycardia were due to the Bainbridge reflex, following decreased auricular pressure, we should expect the greatest slowing of pulse to occur in those subjects with the largest fall of venous pressure. However, Figure 3 (data in Tables 2 and 4) shows that the opposite is the case (the increased venous pressure in Figure $3 C$ is due to errors of selection because of the small number of observations).

The fact that the pulse rate mean chanced not to fall below 95 per cent of the control in our series in no way invalidates the significance of the venous pressure decrease, for in the dogs of Cohn and Stewart (4), the lowest outputs were recorded with a mean pulse rate of 112.5 per cent of the control. Burwell, Neighbors, and Regen (3) also noted that output returned toward normal when their subjects experienced nausea or had more rapid pulses. In one patient with acute hepatitis (not included in this series) in whom digitalis produced partial heart block (pulse rate 41 to 47) and intense nausea and vomiting of four days duration, the venous pressure fell only 1.4 and $0.8 \mathrm{~cm}$. at 5 and 11 hours respectively. The ef- 
fect of digitalis in reducing venous pressure is powerful enough, then, to overcome the counteracting effect of digitalis bradycardia (which, unopposed, would increase auricular pressure).

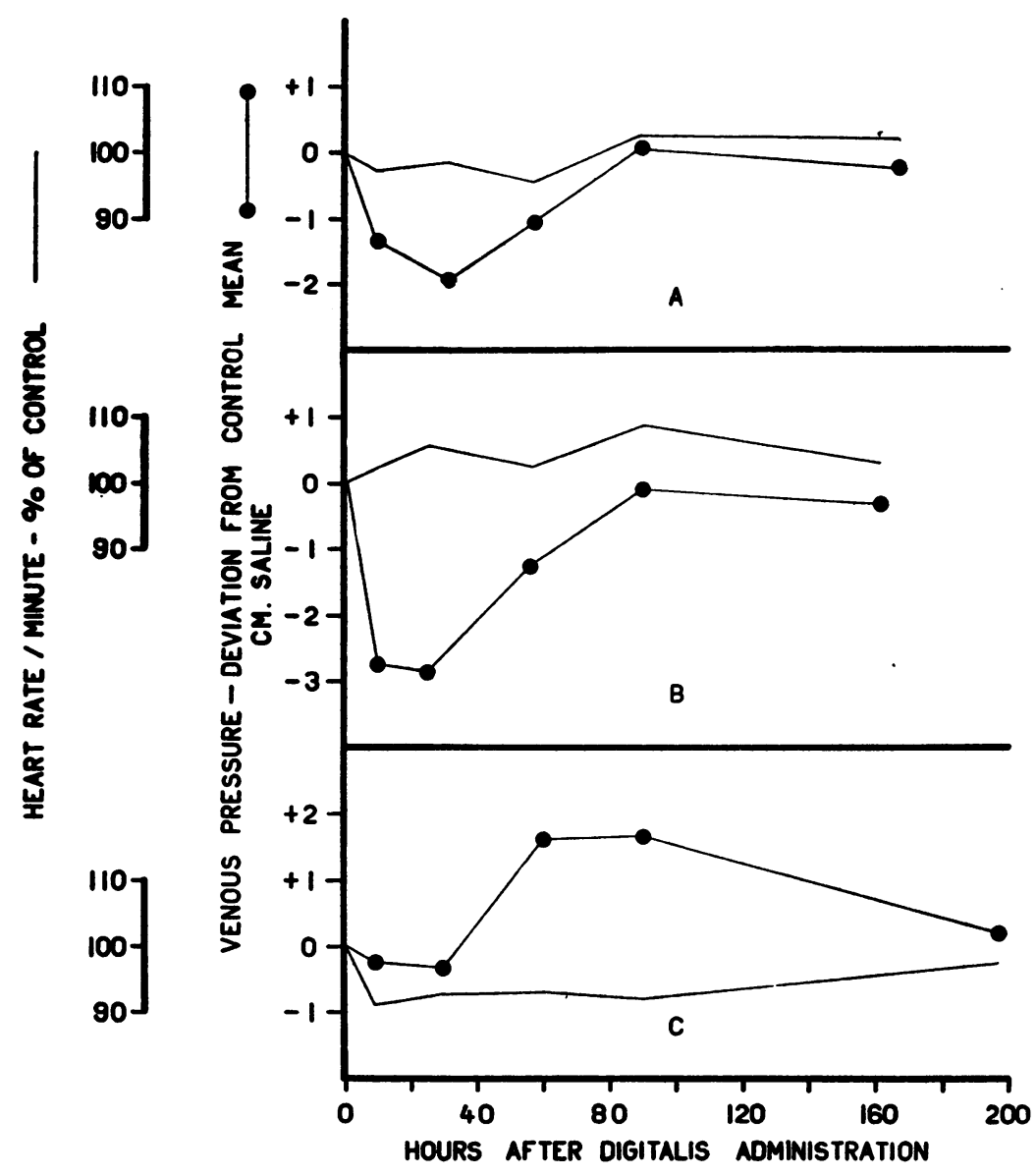

Fig. 3. The Relation of Pulse Rate to Venous Pressure

$A$. Means of all observations. $B$. Means of those with least slowing of pulse. $C$. Means of those with greatest slowing of pulse. (In $C$ the apparent rise of venous pressure is due to the small number of observations between 40 and 120 hours after giving digitalis.)

The production of decreased venous pressure. The hypothesis advanced by Dock and Tainter $(5,6,31)$ to account for the lowered venous pressure and cardiac output after digitalis is that this drug constricts the hepatic veins, resulting in diminished return flow through the inferior vena cava. References to earlier workers on this "sluice mechanism" are given in their papers, along with their corroboratory experimental data. The 
TABLE 4

Relation of venous pressure to pulse rate

\begin{tabular}{|c|c|c|c|}
\hline $\begin{array}{c}\text { Hours after } \\
\text { digitalis } \\
\text { administration }\end{array}$ & $\begin{array}{c}\text { Number } \\
\text { of } \\
\text { observations }\end{array}$ & $\begin{array}{l}\text { Venous pressure. } \\
\text { Deviation from } \\
\text { control mean }\end{array}$ & $\begin{array}{l}\text { Pulse rate. } \\
\text { Percentage } \\
\text { of control }\end{array}$ \\
\hline hours & number & cm. saline & per cent \\
\hline \multicolumn{4}{|c|}{ A. Means of all subjects } \\
\hline $\begin{array}{r}9.3 \\
31.7 \\
57.3 \\
88.9 \\
167.8\end{array}$ & $\begin{array}{l}34 \\
14 \\
12 \\
10 \\
12\end{array}$ & $\begin{array}{r}-1.35 \\
-1.96 \\
-1.08 \\
+0.06 \\
-0.28\end{array}$ & $\begin{array}{r}97.0 \\
98.5 \\
95.6 \\
102.5 \\
102.1\end{array}$ \\
\hline
\end{tabular}

$B$. Means of subjects with least slowing of pulse in the first 36 hours

\begin{tabular}{r|r|r|r}
\hline 9.4 & 15 & -2.75 & 102.4 \\
25.6 & 7 & -2.88 & 105.8 \\
56.3 & 7 & -1.24 & 102.3 \\
88.9 & 7 & -0.11 & 108.7 \\
161.8 & 10 & -0.38 & 103.0 \\
\hline
\end{tabular}

C. Means of subjects with greatest slowing of pulse in the first 36 hours

\begin{tabular}{r|r|r|r}
\hline 9.0 & 14 & -0.24 & 91.0 \\
30.7 & 4 & -0.33 & 92.7 \\
60.5 & 2 & +1.60 & 93.0 \\
89.2 & 2 & +1.65 & 92.0 \\
197.6 & 2 & +0.20 & 97.5 \\
\hline
\end{tabular}

hypothesis is confirmed by the results of other. workers $(15,16,17)$. Cohn and Steele (18) state that " in order to be effective in shutting off from the volume of blood returning to the right auricle as much as a quarter, the lumina of the two vessels" [right and left hepatic veins] " must be reduced to zero-must be completely obliterated." However, Blalock and Bradburn (32) produced a 75 per cent reduction in cardiac output by intestinal trauma and associated altered circulatory state in the portal area; Elman and Cole (33) found that approximately 60 per cent of the total blood volume accumulates in the splanchnic area within a short time after portal vein ligation; Enderlen and coworkers (34) found that death occurs from reduced arterial pressure and cardiac output in 10 to 60 minutes after portal vein occlusion. With such dramatic results following the prevention of portal outflow, it is easily possible that digitalis should lower cardiac output only 20 per cent and venous pressure $2 \mathrm{~cm}$. by constricting hepatic vein radicles.

The anatomic evidence for the "sluice mechanism" has been investigated in cats, dogs, and human beings by Elias and Feller (36), Popper 
(37), and Bauer, Dale, Poulsson, and Richards (35) ; the subject is reviewed by the latter. In brief, the findings suggest that in the dog the mechanism is brought about by the anatomic construction at the caval openings of the hepatic veins; in the cat and in man the hepatic vein radicles probably play a more important rôle. Whether the greater sensitivity of the dog to digitalis action on cardiac output (Fig. 2) may be attributed to the anatomic findings is not known.

Clinical applications. The reduction in heart size noted by Stewart and Cohn (7) is undoubtedly due to the digitalis effects studied above; such action, if sustained, would retard cardiac hypertrophy. In a recent paper, Christian (38) proposes continuous complete digitalization of patients with enlarged hearts (and of those in whom cardiac enlargement may be expected) while compensated, under the clinical impression that enlargement and decompensation are retarded. Because of the importance of this subject, the impression should be confirmed or disproved by experiments designed to determine how long the digitalis effect on heart size, venous pressure, and cardiac output can be sustained in animals, normal human beings, and those compensated patients whom Christian suggests digitalizing to retard heart failure.

\section{CONCLUSIONS}

1. Digitalis causes, in normal human beings and dogs, a decreased cardiac output and a decreased venous pressure. The greatest effect occurs at about 24 to 32 hours after administration of the drug, with a return to normal levels in 72 to 96 hours.

2. The observed changes support the hypothesis that digitalis owes its action to a peripheral effect, probably on the hepatic vein radicles, in reducing the return flow of blood to the heart. The hypothesis that the digitalis action follows changes in cardiac tone is negatived by all available data.

3. Digitalis bradycardia is not due to the fall of venous pressure. On the contrary, the slowing of the heart, by causing the normal increase in venous pressure, partially conceals the effect of digitalis in reducing the return flow of blood to the heart.

The author takes this opportunity to thank Dr. William Dock for assistance in the preparation of this paper.

\section{BIBLIOGRAPHY}

1. Grollman, A., The Cardiac Output of Man in Health and Disease. Charles C. Thomas, Springfield and Baltimore, 1932, p. 177.

2. Harrison, T. R., and Leonard, B. W., J. Clin. Invest., 1926, iii, 1. The Effect of Digitalis on the Cardiac Output of Dogs and Its Bearing on the Action of the Drug in Heart Disease.

3. Burwell, C. S., Neighbors, De. W., and Regen, E. M., J. Clin. Invest., 1928, $\mathrm{v}, 125$. The Effect of Digitalis upon the Output of the Heart in Normal Man. 
4. Cohn, A. E., and Stewart, H. J., J. Clin. Invest., 1928, vi, 53. The Relation Between Cardiac Size and Cardiac Output per Minute Following the Administration of Digitalis in Normal Dogs.

5. Dock, W., and Tainter, M. L., J. Clin. Invest., 1929-30, viii, 467. The Circulatory Changes after Full Therapeutic Doses of Digitalis, with a Critical Discussion of Views on Cardiac Output.

6. Tainter, M. L., and Dock, W., J. Clin. Invest., 1929-30, viii, 485. Further Observations on the Circulatory Actions of Digitalis and Strophanthus with Special Reference to the Liver and Comparisons with Histamine and Epinephrine.

7. Stewart, H. J., and Cohn, A. E., J. Clin. Invest., 1932, xi, 917. Studies on the Effect of the Action of Digitalis on the Output of Blood from the Heart. III. Part 1. The Effect on the Output in Normal Human Hearts. Part 2. The Effect on the Output of Hearts in Heart Failure with Congestion, in Human Beings.

8. Villaret, M., Saint-Girons, F., and Justin-Besançon, L. La Pression Veineuse Périphérique. Masson, Paris, 1930, p. 278.

9. Kaufmann, M., Rev. de méd., 1884, iv, 381. Effets physiologiques de la digitaline amorphe.

10. Popper, J., Ztschr. f. klin. Med., 1889, xvi, 97. Ueber die physiologische Wirkung des Strophantins.

11. Plumier, L., Arch. internat. de Physiol., 1909, viii, 1. Etude expérimentale des variations de la pression veineuse.

12. Yokota, M., Tohoku. J. Exper. Med., 1923, iv, 23. Uber die Wirkung der Arzneimittel auf den Blutdruck, besonders den venösen.

13. Capps, J. A., and Matthews, S. A., J. A. M. A., 1913, 1xi, 388. Venous Blood Pressure as Influenced by the Drugs Employed in Cardiovascular Therapy.

14. Eyster, J. A. E., Tr. A. Am. Physicians, 1928, xliii, 17. (In discussion on paper of Cohn and Stewart.)

15. Wollheim, E., Klin. Wchnschr., 1928, vii, 1261. Kompensation und Dekompensation des Kreislaufs.

16. Schïrmeyer, A. (Quoted by Mies (17).)

17. Mies, H., Verhandl. d. deutsch. Gesellsch. f. Kreislaufforsch., 1931, p. 208. Ueber die Wirkung des Strophanthin auf die zirkulierende Blutmenge.

18. Cohn, A. E., and Steele, J. M., J. Clin. Invest., 1932, xi, 871. Studies on the Effect of the Action of Digitalis on the Output of Blood from the Heart. I. The Effect on the Output of the Dog's Heart in Heart-Lung Preparations.

19. Stewart, H. J., and Cohn, A. E., J. Clin. Invest., 1932, xi, 897. Studies on the Effect of the Action of Digitalis on the Output of Blood from the Heart. II. The Effect on the Output of the Hearts of Dogs Subject to Artificial Auricular Fibrillation.

20. Moritz, F., and Tabora, D., Deutsches Arch. f. klin. Med., 1921, xcviii, 475. Uber eine Methode, beim Menschen den Druck in oberflächlichen Venen exakt $z u$ bestimmen.

21. White, H. L., Am. J. Physiol., 1924, lxix, 410. Circulatory Responses to Exercise in Man and their Bearing on the Question of Diastolic Heart Tone.

22. Evans, W., New Eng. J. Med., 1932, ccvii, 934. Venous Pressure.

23. Hooker, D. R., Am. J. Physiol., 1914, xxxv, 73. Observations on the Venous Blood Pressure in Man. 
24. Cohn, A. E., Fraser, F. R., and Jamieson, R. A., J. Exper. Med., 1915, xxi, 593. The Influence of Digitalis on the $T$ Wave of the Human Electrocardiogram.

25. White, P. D., and Sattler, R. R., J. Exper. Med., 1916, xxiii, 613. The Effect of Digitalis on the Normal Human Electrocardiogram, with Especial Reference to A-V Conduction.

26. Bromer, A. W., and Blumgart, H. L., J. A. M. A., 1929, xcii, 204. The Maintenance Dose of Digitalis. An Electrocardiographic Study.

27. Beck, C. S., and Isaac, L., J. Thoracic Surg., 1931, i, 124. Pneumocardiac Tamponade. A Study of the Effects of Atmospheric Pressure, Negative Pressure and Positive Pressure upon the Heart.

28. Wiggers, C. J., Modern Aspects of the Circulation in Health and Disease. Lea and Febiger, Philadelphia and New York, 1923, 2d ed., p. 107, fig. 31.

29. Starling, E. H., and Visscher, M. B., J. Physiol., 1927, 1xii, 243. The Regulation of the Energy Output of the Heart.

30. Wiggers, C. J., and Stimson, B., J. Pharmacol. and Exper. Therap., 1927, xxx, 251. Studies on the Cardiodynamic Action of Drugs. III. The Mechanism of Cardiac Stimulation by Digitalis and g-Strophanthin.

31. Tainter, M. L., Arch. internat. de Pharmacodyn. et de thérap., 1932, xlii, 186. Use of the Gibbs Artificial Heart in the Study of Circulatory Phenomena, with Descriptions of Improvements in the Device and of Responses to Some Drugs.

32. Blalock, A., and Bradburn, H., Arch. Surg., 1930, xx, 26. Distribution of the Blood in Shock.

33. Elman, R., and Cole, W. H., Proc. Soc. Exper. Biol. and Med., 1932, xxix, 1122. Loss of Blood as a Factor in Death from Acute Portal Obstruction.

34. Enderlen, Hotz, and Magnus-Alsleben, Ztschr. f. d. ges. exper. Med., 1914, iii, 223. Die Pathologie und Therapie des Pfortaderverschlusses.

35. Bauer, W., Dale, H. H., Poulsson, L. T., and Richards, D. W., J. Physiol., 1932, lxxiv, 343. The Control of Circulation through the Liver.

36. Elias, H., and Feller, A. Stauungstypen bei Kreislaufstörungen. Springer, Wien. u. Berlin, 1926.

37. Popper, H., Klin. Wchnschr., 1931, x, 1693, 2129. Ueber Drosselvorrichtungen an Lebervenen.

38. Christian, H. A., J. A. M. A., 1933, c, 789. The Use of Digitalis other than in the Treatment of Cardiac Decompensation. 